\title{
Description of a new species of Saphonecrus Dalla Torre \& Kieffer from China (Hymenoptera: Cynipidae: Synergini)
}

\author{
Juli Pujade-Villar, Yiping Wang* \& Rui Guo
}

Pujade-Villar, J., Wang, Y. \& Guo, R. 2014: Description of a new species of Saphonecrus Dalla Torre \& Kieffer from China (Hymenoptera: Cynipidae: Synergini). - Entomol. Fennica 25: 43-48.

A new inquiline species of Saphonecrus Dalla Torre \& Kieffer, S. reticulatus sp. n., is described with its host gall. This species emerged from stem galls on Quercus aliena var. acutiserrata (Fagaceae). Diagnosis, distribution, and biology of the new species are included and the most important morphological characters are illustrated.

J. Pujade-Villar, Department of Animal Biology, Barcelona University, Barcelona 08028, Spain

Y. Wang, College of Forest and Biotechnology, Zhejiang Agricultural and Forestry University, Lin'an 311300, China; *Corresponding author's e-mail: ypwang123@gmail.com

R. Guo, Administration Bureau of Zhejiang Qingliangfeng National Nature Reserve, Lin'an 311300, China

Received 18 April 2013, accepted 12 August 2013

\section{Introduction}

Saphonecrus is an inquiline genus associated with oak gallwasps (Cynipini). Inquilines have retained the ability to modify the gall tissue directly surrounding them into the characteristic nutritive tissue also found in the larval chambers of the gall inducer, but they have lost the ability to initiate the gall. Nevertheless, a few inquiline species are mentioned as gallinducers (Abe et al. 2011, Liu et al. 2012, Bernardo et al., in press).

Saphonecrus is represented by 23 species distributed in the northern hemisphere but only six of them are mentioned from China: $S$. sinicus Belizin, 1968; S. chaodongzhui Melika, Ács \& Bechtold, 2004; S. flavitibilis Wang \& Chen, 2010 (in Wang et al. 2010); S. tianmushanus Wang \& Chen, 2010 (in Wang et al. 2010); S. naiquanlini Melika, Ács \& Bechtold, 2004 and $S$. hupingshanensis Liu, Yang \& Zhu, 2012. Al- though the systematic status of the genus has long been considered to be in need of revision (PujadeVillar \& Nieves-Aldrey 1990, Pujade-Villar et al. 2003, Melika 2006, Penzes et al. 2009, 2012), the changes are not formally published for this. We report a new species of Saphonecrus according to the current definition of the genus.

\section{Material and methods}

The specimens from China used in this study are from the Hymenoptera Collection, Zhejiang Agricultural and Forest University, Lin'an, China (ZJUH).

We followed the current terminology of cynipid gallwasp morphology (Liljeblad \& Ronquist 1998, Melika 2006). Abbreviations for the forewing venation followed Ronquist and Nordlander (1989), terminology of cuticular sur- 
face followed that of Harris (1979). Measurements and abbreviations used here include:

- F1-F12, first and subsequent flagellomeres

- POL, post-ocellar distance, the distance between the inner margins of the posterior ocelli

- OOL, ocellar-ocular distance, the distance from the outer edge of the posterior ocellus to the inner margin of the compound eye

- LOL, the distance between lateral and frontal ocelli

The width of the forewing radial cell was measured from the margin of the wing to the Rs vein.

Descriptions and measurements were made under a Leica MZ 12.5 stereomicroscope (Wetzlar, Germany). Photos for Fig. 1 were taken by a digital camera (Q-Imaging, Micropublisher 3.3 RTV) attached to a Leica MZ APO stereomicroscope (Wetzlar, Germany) using Synoptics Auto- Montage version 5.0 software. For Fig. 2, the field-emission gun environmental scanning electron microscope (FEI Quanta 200 ESEM) was used for high-resolution imaging without gold-coating.

All type specimens are deposited in the Hymenoptera Collection of ZJUH and UB (University of Barcelona, coll. JP-V).

\section{Description of Saphonecrus reticulatus sp. n. (Figs 1, 2)}

Type specimens examined. Holotype: $\uparrow$, deposited in ZJUH: China, Zhejiang, Xitianmu Mountain $119^{\circ} 27$ E, $30^{\circ} 19$ N), 19.VI., Rui Guo leg. Paratypes: 5 우, with same data as the holotype (one deposited in UB).

Diagnosis. The species here described differs from all species of Saphonecrus by having a mesopleuron partially reticulated; all known species of Saphonecrus have a carinated mesopleuron (except $S$. diversus, smooth). The new species has pronotal carina, nevertheless differs from the Saphonecrus with pronotal carina (S. haimi, $S$. irani, S. shirakashii, S. shirokashicola, S. undulatus, $S$. areolatus and $S$. serratus) by having also the strong sculpture. The new species is defined by a combination of the following features: body color black; lateral frontal carina and lateral pronotal carina present; antennae with 11 flagellomeres; tarsal claws with a basal tooth; mesopleuron carinated, partially reticulated; scutellar foveae with longitudinal carinae; notauli complete; medial line very long; and fused segments $2+3$ of metasoma with a vertical line of 5-6 setae. This species is related morphologically to $S$. hupingshanensis having the fronts strongly punctuated, but can differentiated by $S$. hupingshanensis having head orange, antennae with 14 segments, mesopleuron without reticulated sculpture and suture of metasomal fused $2+3$ present.

Description. Length. Female $2.0 \mathrm{~mm}$, male unknown.

Colour. Body black. Antenna pale yellow medially, and darker pale brown basally and apically. Wing hyaline, with distinct brownish veins.

Head (Fig. 1a, b, e, 2a-c). Head delicately coriaceous, with dense white setae; 1.8 times as wide as median length in dorsal view, 1.4 times as wide as high in front view and slightly narrower than mesosoma. Gena rugose, not broadened behind eye, invisible in front view, narrower than cross diameter of eye, measuring behind eye. POL: $L O L:$ OOL $=2.5: 1.3: 1.5$, OOL two times as long as diameter of lateral ocellus. Transfacial distance 1.2 times as long as height of eye; diameter of antennal torulus 1.5 times as long as distance between them, distance between torulus and eye margin 1.3 times as long as diameter of torulus. Inner margins of eyes curved. Face with a medial distinct carina from antennal torulus to clypeus. Lower face delicately coriaceous, with sparse white setae and dense delicate striae irradiating from clypeus, and reaching eye and ventral margin of toruli. Clypeus inconspicuous, with distinct small anterior tentorial pits; epistomal sulcus indistinct; clypeo-pleurostomal lines indistinct, ventral margin straight, without incision medially. Frons and vertex strongly coriaceous and strongly punctuate, with some longitudinal carina between punctures; lateral frontal carina distinct but weakly impressed, extending to lateral ocelli; occiput strongly coriaceous with some rugae.

Antenna (Fig. 1d). Antenna 13-segmented, slightly longer than head plus mesosoma; scape with dense setae; pedicel 1.6 times as long as wide; F1 1.3 times as long as F2 and 1.7 times as 


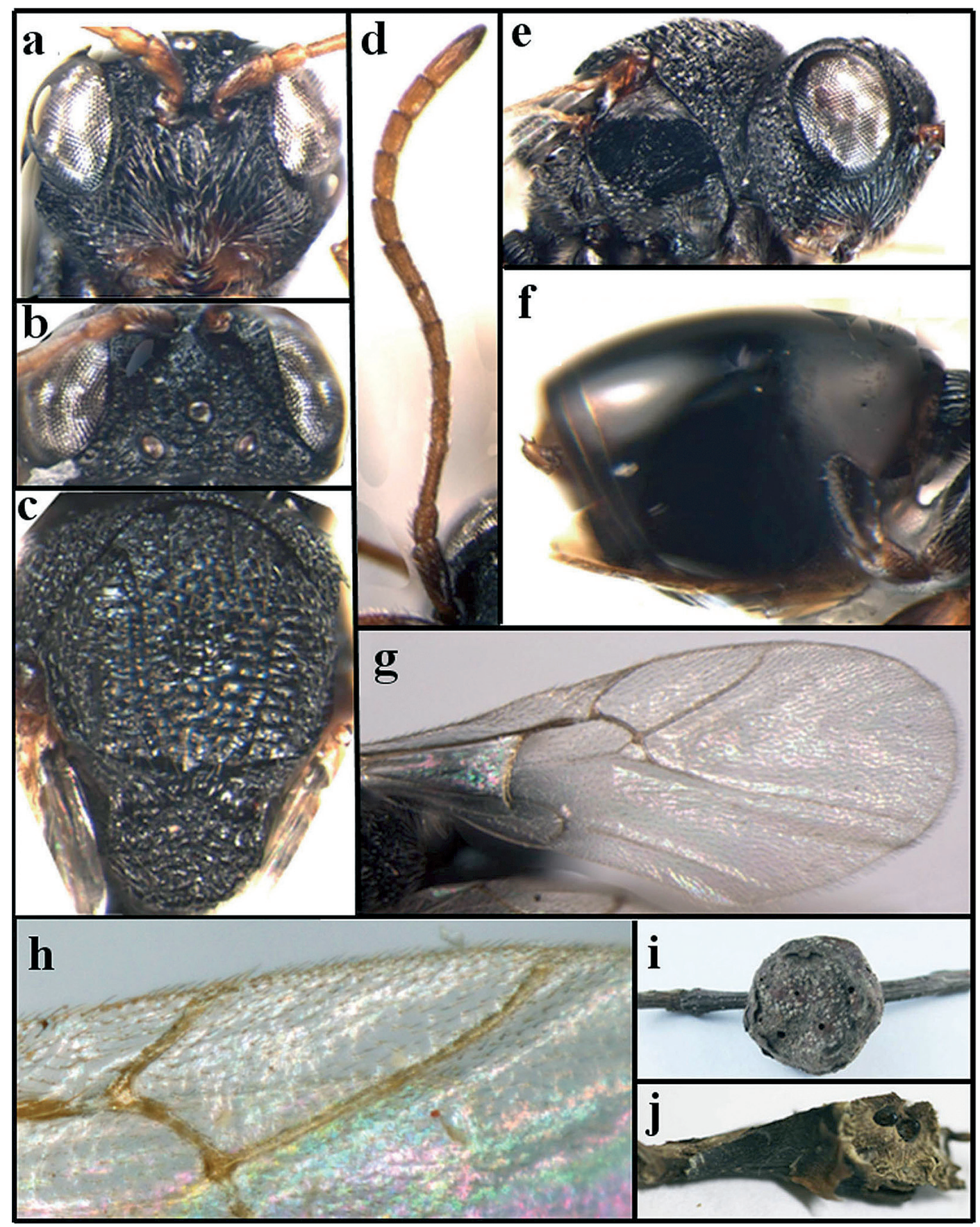

Fig. 1. Saphonecrus reticulatus sp. n. - a. Head, anterior view. - b. Head, dorsal view. - c. Mesosoma, dorsal view. - d. Antenna. - e. Mesosoma, lateral view. - f. Metasoma, lateral view. - g. Forewing. - h. Radial cell of fore wing. - i. Gall. - j. Gall, cut-off.

long as pedicel; F11 1.9 times as long as F10; relative lengths of antennal segments from scape to F11: 19: 8: 13: 10: 8: 8: 8: 11: 10: 10:9: 9: 17.

Mesosoma (Fig. 1c, e, 2c-e). Mesosoma con- vex, slightly longer than height in lateral view, with dense white setae. Pronotum carinated laterally with interspaces strongly coriaceous. Mesoscutum strongly coriaceous, slightly longer than 


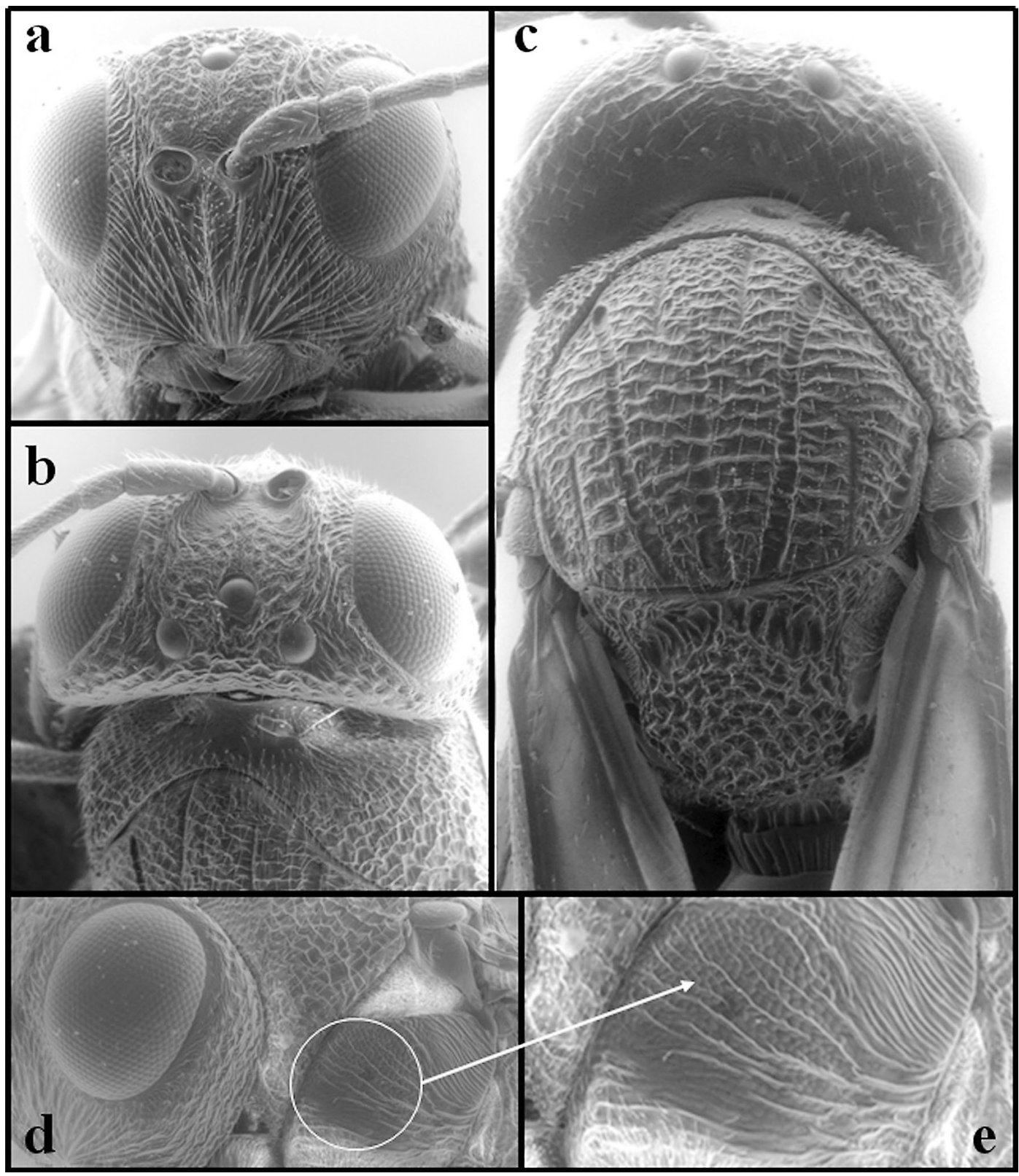

Fig. 2. Saphonecrus reticulatus sp. n. - a. Head, anterior view. - b. Head, dorsal view. - c. Head and mesosoma, dorsal view. - d. Mesopleuron. - e. A detail of mesopleuron.

wide, with distinct transverse carinae and few white setae. Notauli complete, well-impressed along entire length of mesoscutum, weakly converging posteriorly; median mesoscutal line extending to $2 / 3$ of mesoscutum length; parapsidal lines distinct and extending to $1 / 4$ of mesoscutum length; anterior parallel lines distinct and visible and extending to $1 / 3$ of mesoscutum length.
Mesoscutellum rugose, slightly longer than wide, with some transverse carinae. Scutellar foveae deeply impressed, confluent or separated by a weak carina, bottom alutaceous with longitudinal carina. Mesopleuron with distinctly interrupted delicate longitudinal striae, reticulate in the anterior part and between carina; speculum smooth and shiny, without setae; mesopleural triangle 
densely setose. Metapleural sulcus reaching mesopleuron in 3/4 of its height. Lateral propodeal carina distinct, subparallel and slightly convergent posteriorly; median propodeal area alutaceous, with longitudinal rugae and dense setae.

Legs. Tarsal claws with large basal lobe and tooth.

Wing (Fig. 1g-h). Forewing longer than body, margin with long cilia; radial cell opened, 2.6 times as long as its maximum width; areolet distinct; vein Rs $+\mathrm{M}$ well-marked and extending to half of entire distance between areolet and basal vein.

Metasoma (Fig. 1f). Metasoma slightly longer than head plus mesosoma, and 1.35 times as long as its maximum height in lateral view. Fused metasomal tergites $2+3$ with vertical line of white setae anterolaterally, and with micropunctures apically; subsequent tergites with micropunctures and with setae; prominent part of ventral spine of hypopygium very short; hypopygium partially micropunctuate.

Distribution. China (Zhejiang).

Biology. The species was reared from twig galls on Quercus aliena Blume var. acutiserrata Maxim. (section Quercus). The gall (Fig. 1i-j) is a swelling on branches and twigs, usually located in the middle of the twig, not apically; sometimes swellings are at joints of twigs; up to $3 \mathrm{~cm}$ long, $1.5-1.8 \mathrm{~cm}$ in diameter, the same colour as the bark of twigs. When the gall is mature, tissues are hard and lignified. Larval chambers are arranged perpendicularly to main axis of gall, radiating from center of twig toward gall surface, reaching to $2-3 \mathrm{~mm}$ from surface. Mature galls were collected in late June, adult inquilines emerged under laboratory conditions immediately after gall collecting.

Etymology. The new species is named after the reticulate mesopleuron.

\section{Discussion}

The genus Saphonecrus was established by Dalla Torre and Kieffer (1910) for the oak inquiline species with an open radial cell. Pujade-Villar and Nieves-Aldrey (1990) revised the European species and maintained the genus, but also questioned its validity. Although the separation of this genus from Synergus has subsequently been widely questioned (Eady \& Quinlan 1963, Ritchie 1984, Pujade-Villar \& Nieves-Aldrey 1990), the two genera have never been formally synonymized.

Penzés et al. (2012) consider Saphonecrus to be polyphyletic and closely allied to Synergus. Indeed, Gorge Melika \& Juli Pujade-Villar have been trying for a long time, still unsuccessfully, to establish the limits between Synergus-Saphonecrus and some genera still not described which would include species now belonging to Synergus or to Saphonecrus. This is a complex problem which has to take into account all the variation in the group. The species now described, Saphonecrus reticulatus $\mathbf{s p .} \mathbf{n}$. may be an important link of this conflict. On the other hand, the solution of the complex Synergus-Saphonecrus in monophyletic groups is far away of being solved, because, until now, the molecular analyses have not given a clear indication for resolving the conflict. But this fact should not prevent to describe peculiar species in this group as has happened in recent years (Saphonecrus: $S$ flavitibilis Wang \& Chen, 2010, S. tianmushanus Wang \& Chen, 2010, S. yukawai Wachi, Ide \& Abe, 2011, S. hupingshanensis Liu et al. 2012; Synergus: S. baruensis Nieves-Aldrey \& Medianero, 2011, S. chiricanus Nieves-Aldrey \& Medianero, 2011, S. elegans Nieves-Aldrey \& Medianero, 2011, S. itoensis Abe et al. 2011, S. castaneus Pujade-Villar, Bernardo \& Viggiani, 2013, among others). These are important advances in the knowledge of the group.

The species described in this study is very unusual, because it has the mesopleura with reticulate sculpture. This sculpture is not present in any other known species of Synergus and Saphonecrus. Except this character, there is no doubt that this is a Saphonecrus species (understanding this as an inquiline morphological group, currently recognized). The reticulated mesopleura is present only in an undescribed genus collected in galls induced in Lithocarpus; the description of this genus is in this moment under evaluation for publication. The species described here doesn't belong to this related new genus according to its host plant (the new species was not collected in Lithocarpus galls but Quercus galls) and according to its specific morphological characters. 
In conclusion, the variability of Saphonecrus 'sensu lato' is expanded with the description of this new species.

Acknowledgements. We are very grateful to George Melika (Plant Health and Molecular Biology Laboratory, Budapest, Hungary) for his comments about this new species. The project was supported by a research grant from National Natural Science Foundation of China (31071970), Zhejiang Natural Science Fund for Distinguished Young Scholars (R14C040002).

\section{References}

Abe, Y., Ide, T. \& Wachi, N. 2011: Discovery of a New Gall-Inducing Species in the Inquiline Tribe Synergini (Hymenoptera: Cynipidae): Inconsistent Implications from Biology and Morphology. - Annals of the Entomological Society of America 104: 115-120.

Bernardo, U., Gebiola, M., Xiao, Z., Zhu, C. D., PujadeVillar, J. \& Viggiani, G. 2013: Description of Synergus castaneus n. sp. (Hymenoptera: Cynipidae: Synergini), associated with an unknown gall on Castanea spp. (Fagaceae) in China. - Annals of the Entomological Society of America 106(4): 437-446.

Dalla Torre, K. W. \& Kieffer, J. J. 1910: Cynipidae. Das Tierreich, 24. Berlin, Friedlander \& Sohn 35: 1-891.

Eady, R. D. \& Quinlan, J. 1963: Hymenoptera: Cynipoidea. key to families and subfamilies and Cynipinae (including galls). - Handbooks for the Identification of British Insects 8(1a): 1-81.

Harris, R. 1979: A glossary of surface sculpturing. State of California, Department of Food and Agriculture. Occasional Papers of Entomology 28: 1-31.

Liljeblad, J. \& Ronquist, F. 1998: A phylogenetic analysis of higher-level gall wasp relationships (Hymenoptera: Cynipidae). - Systematic Entomology 23: 229-252.

Liu, Z., Yang, X. H., Zhu, D. H. \& He, Y. Y. 2012: A New
Species of Saphonecrus (Hymenoptera, Cynipoidea) Associated with Plant Galls on Castanopsis (Fagaceae) in China. - Annals of the Entomological Society of America 105(4): 555-561.

Melika, G. 2006: Gall Wasps of Ukraine. Cynipidae. Vestnik Zoologii, Suppl. 21(1): 1-300.

Penzes, Z., Melika, G., Bozsoki, Z., Bihari, P., Miko, I., Tavakoli, M., Pujade-Villar, J., Feher, B., Fulop, D., Szabo, K., Bozso, M., Sipos, B., Somogyi, K. \& Stone, G. 2009: Systematic reappraisal of the gall-usurping wasp genus Synophrus Hartig, 1843 (Hymenoptera: Cynipidae: Synergini). — Systematic Entomology 34: 688-711.

Penzes, Z., Tang, C. T., Bihari, P., Bozsó, M., Schwéger S. \& Melika, G., 2012: Oak associated inquilines (Hymenoptera, Cynipidae, Synergini). — TISCIA monograph series 11, Szeged (Hungary), $76 \mathrm{pp}$.

Pujade-Villar, J., Melika, G., Ros-Farre, P., Ács, Z. \& Csoka, G. 2003: Cynipid inquiline wasps of Hungary, with taxonomic notes on the Western Palaearctic fauna (Hymenoptera: Cynipidae, Cynipinae, Synergini). Folia Entomologica Hungarica 64: 121-170.

Pujade-Villar, J., \& Nieves-Aldrey, J. L. 1990: Revisión de las especies europeas del género Saphonecrus Dalla Torre y Kieffer, 910 (Hym., Cynipidae, Cynipinae). Butlletí de la Institució Catalana d'Histìria Natural (Ser. Zool.) 58: 45-55.

Ritchie, A. J. 1984: A review of the higher classification of the inquiline gall wasps (Hymenoptera: Cynipidae) and a revision of the Nearctic species of Periclistus Förster. Ph. D. diss. Carleton University, Ottawa.

Ronquist, F. \& Nordlander, G. 1989: Skeletal morphology of an archaic cynipoid, Ibalia rufipes (Hymenoptera: Ibaliidae). - Entomological Scandinavica supplement 33: 1-60.

Wang Y. P., Chen X. X., Pujade-Villar, J., Wu, H. \& He, J. H. 2010: The genus Saphonecrus Dalla Torre et Kieffer, 1910 (Hymenoptera: Cynipidae) in China, with descriptions of two new species. - Biologia 65(6): 1034-1039. 